\title{
Güzellik Uzmanlarının Mesleki Uyg. ile ilişsili Olabilecek Bulaşıcı Hastalık Ve Hijyen Konularındaki Bilgi, Tutum Ve Davranışlarının Değerlendirilmesi
}

\author{
Investigation of Cosmeticians' Knowledge, Attitudes and Behaviors About
} Communicable Diseases and Hygiene in Occupational Practices and Related Factors

Gülsüm Sözen', Oğuz Karabay², Meltem Pınar Karabel’3, Mine Keskin³, Hilal Karahan 33, Mustafa Baran İnci33, Aziz Öğütlï̈4, Ertuğrul Güçlï², Hasan Çetin Ekerbiçer

'Sakarya Üniversitesi, Sağlık Bilimleri Enstitüsü, Sakarya

${ }^{2}$ Sakarya Üniversitesi, Enfeksiyon Hastalıkları ve Klinik Mikrobiyoloji Ana Bilim Dall, Sakarya

${ }^{3}$ Sakarya Üniversitesi, Halk Sağlığı Ana Bilim Dalı, Sakarya

${ }^{4}$ Sakarya ill Sağllık Müdürlüğü, Sakarya

Yazışma Adresi / Correspondence:

Meltem Pınar Karabel

Sakarya Üniversitesi Tıp Fakültesi Halk Sağlığı Anabilim Dalı, Korucuk Mah. Konuralp Bulvarı No:81/1 Korucuk Kampüsü,

Adapazarı/Sakarya

T: +905465839020 E-mail: meltemkarabel@yandex.com

Geliş Tarihi / Received : 07.03.2018 Kabul Tarihi / Accepted : 19.03.2018

\footnotetext{
Öz

Amaç Bu çalıșmada güzellik uzmanlarının bazı sosyodemografik özellikleri, işyeriyle ilişkili bulaşııı hastalıklar ve hijyen konuları hakkında bilgi ve tutumları, verdikleri hizmet sırasında uyguladıkları hijyen ve dezenfeksiyon uygulamalarının değerlendirilmesi amaçlandı. ( Sakarya Tip Dergisi 2018, 8(1):70-79)

Metod Tanımlayıcı tipteki araştırma, 22.10.2017 tarihinde Antalya'da düzenlenen 17. Uluslararası Güzellik ve Kozmetoloji Kongresi'ne Türkiye genelinden katılan 200 güzellik uzmanından araştırmaya katılmayı kabul eden 98 kişi üzerinde yapııldı. Veriler, araştırmacılar tarafından literatür desteğiyle hazırlanan 26 soruluk bir anket formu yardımılla toplandı.

Bulgular Katılımcıların; \%91,7'si kadın, \%59,2'si lise mezunu, \%30,6'sı üniversite mezunu, \%36,7'si meslekte 10 yildan daha fazla süredir çalışmaktaydı. Katıtımcıların \%75,8'i HIV(AIDS)'in, \%74,7'ü Hepatit B'nin, \%66,3'ü Hepatit C'nin kozmetik uygulamalar sırasında bulaşabileceğini belirtti. Meslekte çalışma süresi 10 yıl ve daha az olanların \%83,9'u, 10 yıldan daha fazla süredir çalışanların \%64,5'i HIV enfeksiyonun güzellik salonlarından bulaşabileceğini ifade etti. Tüm grupta HBV aşısı yaptırma oranı \%78,7'ydi. Kullandıkları araç ve gereçlerin dezenfeksiyonunu sağlama yöntemleri sorusuna verilen cevapların \%37,0'sini ultraviyole sterilizatör, \%25,9'unu dezenfektan solüsyonlar oluşturdu.

Sonuç Özellikle kan yoluyla bulaşan enfeksiyon etkenleri ile ilgili bilgi sahibi olanların oranları benzer çalışmalara göre yüksek bulunmuş olmakla birlikte bu konularda yetersiz bilgiye sahip olmak, bu meslek grubu için kabul edilebilir bir durum değildir. Bu nedenle güzellik uzmanlarına eğitimleri sırasında mesleki uygulamaları ile ilişkili bulaşıcı hastalıklar hakkında daha fazla bilgi verilmelidir. Tüm çalışanların Hepatit B aşısı yaptırmasının sağlanması hedeflenmeli ve yetkili kurumlarca denetimleri artııılmalıır. Meslekte uzun yıllardır çalışanları da hedefleyen meslek içi eğitimler düzenlenerek, hijyen konusunda uygulamalı eğitimlerle beceri kazandırılmalıdır.

Keywords Hijyen, Kozmetikler, Bulaşıcı hastalıklar, Güzellik, Işs sağlı̆ı
}

\section{Abstract}

Objective In this research, it was aimed to determine the cosmeticians' sociodemographic characteristics, knowledge and attitudes about communicable diseases and hygiene related to the workplace, hygiene and disinfection applications they applied during the service. ( Sakarya Med J 2018, 8(1):70-79).

Material and The descriptive study was carried out at the 17th International Congress of Beauty and Cosmetology in Antalya on 22.10.2017. The data

Method were collected by a standart questionnaire

Results Questionnaires were conducted on 98 of 200 cosmeticians. $91,7 \%$ of the participants were women, 59,2\% were high school graduates, $30,6 \%$ were university graduates, $36,7 \%$ were in profession more than 10 years. $75.8 \%$ of participants stated that HIV, $74.7 \%$ Hepatitis B, $66.3 \%$ Hepatitis C could be transmitted during cosmetic applications. $83.9 \%$ of those who worked for 10 years or less and $64.5 \%$ of those who worked more than 10 years were stated that HIV infection can be transmitted from beauty centers. Overall vaccination rate was $78.7 \%$. $37,0 \%$ of the answers given for the methods of providing the disinfection of the tools and equipment they use are composed of ultraviolet sterilizer and $25,9 \%$ of the answers were disinfectant solutions.

Conclusion It is not acceptable for this profession group to have inadequate knowledge of the causal agents of infection, especially through blood. All beauty centre employees should be targeted for Hepatitis B vaccination. Supervision should be increased by the authorized institutions. Occupational trainings on communicable diseases and hygiene aiming at employees should be organized.

Keywords Hygiene, Cosmetics, Communicable Diseases, Beauty, Occupational Health 
Sakarya Tıp Dergisi 2018;8(1):70-79

\section{Giriş}

Geçmişte sadece saç bakımı hizmeti veren berber ve kuaförlerin yerini alan güzellik uzmanları, kozmetik bilim ve teknolojisinden yararlanarak cildi ve vücudu daha sağlıklı, daha güzel, daha genç göstermek için çaba sarf etmektedir. Kişisel ihtiyaçların değişmesi ile birlikte, saç ve cilt bakımı, manikür-pedikür, ağda, epilasyon, kalıcı makyaj ve benzeri güzellik hizmetleri gibi daha kişiye özel ve para-medikal yanı ağır basan hizmetler sunulmaktadır.

Güzellik ve saç bakım hizmetlerinde çalışanların kişisel hijyenlerine, çalışma aletlerinin dekontaminasyon, dezenfeksiyon ve sterilizasyonuna, atıkların doğru şekilde uzaklaştıılmasına ve ayrıca çalışma ortamının hijyenine gereken önemi vermedikleri takdirde müşteri ve kendilerine hastalık bulaştırmaları kaçınılmazdır. Bu açıdan hizmeti alan ve veren arasında iki yönlü bir risk vardır. Çeşitli taramalarda kişilerin tesadüfen öğrendiği Hepatit $B$ virüsü (HBV), hepatit $C$ virüsü $(\mathrm{HCV})$, insan immün yetmezlik virüsü (HIV) seropozitifliklerinin bir kaynağının da kuaför, berber ve güzellik saIonlarından alınan hizmetler neticesinde olduğu bilinmektedir. ${ }^{1}$

Ülkemizde HBsAg prevalansı ile ilgili yapılan bir metaanaliz sonucu toplumda HBsAg pozitifliğinin \%4.57 yani 3.3 milyon kişi olduğu, 2016 itibarı ile HIV tanısı alan hastaların sayısının 13.181'e ulaştığı bulunmuştur. Bu sayılar göz önünde bulundurulduğunda bu hastalıkların toplumdan bulaşma ihtimaline karşı alınacak önlemlerin ne kadar önemli olduğu anlaşılmaktadır.,3

Güzellik işletmelerinde kullanılan araç ve gereçlerin bir bölümü (sünger, fııça, kartuş, spatula, törpü vb.) çoğunlukla tek seferlik kullanımı olan aletler değildir. Bu aletlerin en büyük riski pek çok kişinin ortak kullanımından kaynaklanan hastalıkların bulaşma ve yayılmasına zemin hazırlamasıdır

Hepatit B, C ve HIV gibi etkenler saç ve kıl diplerinden, tırnak kenarlarından, görünen veya mikroskobik olarak görülebilen kan yoluyla bulaşmaktadır. Mantarlar daha çok küfler olmak üzere insanların yakın teması ile direkt olarak; elbise, tarak, fırça, klozet, çarşaf ile temas sonucu indirekt yolla; Pediculus capitis tarak, fırça kontaminasyonuyla bulaşmaktadır. Dolayısıyla güzellik salonları gerekli hijyen ve dezenfeksiyon kurallarına uyulmaması durumunda bu tür bulaşıcı hastalıkların yayılmasında büyük bir rol oynayabilir. ${ }^{1}$

Tüm dünyada olduğu gibi Türkiye'de de güzellik uzmanlığı mesleği ile ilgili bulaşıcı hastalıklar, hijyen, dezenfeksiyon ve sterilizasyon uygulamaları hakkındaki bilgi ve tutumlarını araştıran çalışma sayısı oldukça azdır. Bu araştırmada güzellik uzmanlarının bazı sosyo-demografik özellikleri (eğitim düzeyi, yaş grubu, cinsiyeti, hizmet verdikleri kişi sayısı), işyeriyle ilişkili bulaşıcı hastalıklar ve hijyen hakkındaki bilgi ve tutumları, verdikleri hizmet sırasında uyguladıkları hijyen ve dezenfeksiyon uygulamalarının tespit edilmesi amaçlandı. Ayrıca çalışmamızdaki katıımcıların Türkiye'nin çeşitli bölgelerinden gelen güzellik uzmanları olması çalışmamııın güçlü yönleri arasındadır.

\section{Materyal Metod}

Tanımlayıcı tipteki bu araştırma, 22.10.2017-27.10.2017 tarihlerinde Antalya'da düzenlenen 17. Uluslararası Güzellik ve Kozmetoloji Kongresi'ne Türkiye genelinden katılan 200 güzellik uzmanından araştırmaya katılmayı kabul eden 98 kişi üzerinde yapıldı. Veriler, araştırmacılar tarafından literatür desteğiyle hazırlanan sosyo-demografik bilgi formu (yaş, cinsiyet, meslekte çalışma yill, en son mezun olduğu okul ve bir günde hizmet verdiği kişi sayısı) ve güzellik uzmanlarının hijyen 
konusunda nereden bilgi edindikleri ve verdikleri hizmet sırasında uyguladıkları hijyen ve dezenfeksiyon uygulamalarının tespit edilmesini amaçlayan 26 soruluk bir anket formu yardımıla toplandı. Anket formunda açık uçlu sorular, tek cevaplı sorular ve çoktan seçmeli sorular bulunmaktaydı.

Araştırma öncesinde Sakarya Üniversitesi Tıp Fakültesi Girişimsel Olmayan Etik Kurul'undan izin alındı.

Kategorik veriler sayı ve yüzdeler ile, sayısal veriler ise ortalama, standart sapma ile özetlendi. Verilerin normal dağılıma uygunluğu Kolmogrov Smirnov ve Shapiro Wilk testleri kullanılarak sınandı. Sosyodemografik özellikler ve kategorik verilerin karşısştırılmasında ki kare testi kullanıldı. Anlamlılık düzeyi $p<0.05$ olarak kabul edilmiştir. Veriler SPSS (Sosyal Bilimler İçin İstatistik Programı) v.20.0 paket programıla analiz edildi.

\section{Bulgular}

Araştırmaya katılanların \%91,7'si (88 kişi) kadın, \%8,3'ü (8 kişi) erkekti. Katılımcların yaşlarının ortalaması $36,21 \pm 8,93$ yıldı. Katılımcıların çalışma yıllarının ortalaması $9,8 \pm 7,57$ yıl, çalışma yılı en az olan katıımcı 6 ay, çalışma yılı en fazla olan 30 yıldır bu işi yapmaktaydı. \%59,2'si (58 kişi) lise mezunu, \%30,6'sı (30kişi) üniversite mezunuydu. Katılımcıların \%47,4'ü (46 kişi) günlük 1-10 kişiye hizmet verdiğini, \%35,1’i (34 kişi) günlük 11-20 kişiye hizmet verdiğini bildirdi (Tablo:1).

\begin{tabular}{|c|c|c|c|}
\hline & & Sayı (n) & Yüzde (\%) \\
\hline \multirow{8}{*}{ Yaş $(n=95)$} & $20-25$ & 13 & 13,7 \\
\hline & $26-30$ & 17 & 17,9 \\
\hline & $31-35$ & 16 & 16,8 \\
\hline & $36-40$ & 14 & 14,7 \\
\hline & $41-45$ & 24 & 25,3 \\
\hline & $46-50$ & 5 & 5,3 \\
\hline & $51-55$ & 5 & 5,3 \\
\hline & $56-60$ & 1 & 1,1 \\
\hline \multirow{6}{*}{ Kıdem (yıl) ( $\mathrm{n=90)}$} & $0-5$ & 34 & 37,8 \\
\hline & $6-10$ & 23 & 25,6 \\
\hline & $11-15$ & 9 & 10 \\
\hline & $16-20$ & 15 & 16,7 \\
\hline & $21-25$ & 5 & 5,6 \\
\hline & $26-30$ & 4 & 4,4 \\
\hline \multirow{5}{*}{ Hizmet verdiği kişi sayısı ( $n=97)$} & 1-10 kişi & 46 & 47,4 \\
\hline & 11-20 kişi & 34 & 35,1 \\
\hline & 21-30 kişi & 11 & 11,3 \\
\hline & 31-40 kişi & 3 & 3,1 \\
\hline & 41 ve üzeri & 3 & 3,1 \\
\hline \multirow{5}{*}{ Mezun olduğu okul (n=98) } & ilkokul & 2 & 2,0 \\
\hline & Ortaokul & 7 & 7,1 \\
\hline & Lise & 58 & 59,2 \\
\hline & Üniversite & 30 & 30,6 \\
\hline & Y.lisans/ Doktora & 1 & 0,1 \\
\hline
\end{tabular}

Sakarya Tip Dergisi 2018;8(1):70-79

SÖZEN ve Ark. Güzellik Uzmanlarnnda Bulaşııı Hastallk ve Hijyen Bilgi Tutum 
Sakarya Tıp Dergisi 2018;8(1):70-79

SÖZEN ve Ark Güzellik Uzmanlarında Bulașici Hastalik ve Hijyen Bilgi Tutum
Araştırmada 95 katılımcıdan \%75,8'i (72 kişi) HIV(AIDS; Edinilmiş Bağışıkıkk Eksikliği Sendromu)'in, \%74,7'si (71 kişi) Hepatit B'nin, \%66,3'ü (63 kişi) Hepatit C'nin, \%93,7'si (89 kişi) mantar hastalıklarının, \%68,4'ü (65 kişi) bitin, \%55,8’i (53 kişi) uyuzun işyeriyle ilişkili olarak bulaşabileceğini tahmin etti.

Araştırmaya katılan güzellik uzmanlarının kıdem yılı 10 yıl ve daha az olanlar, 10 yıldan daha fazla meslekte kıdemli olanlara göre HIV enfeksiyonun güzellik salonlarından bulaşabileceğini yapılan ki kare testine göre anlamlı olarak daha fazla doğru tahmin etti $(p<0,05)$ (Tablo:2).

Tablo 2: Güzellik uzmanlarının kıdem yıllarına göre mesleki uygulamaları sırasında bulaşma riski olan bazı hastalkkları bilme durumları

\begin{tabular}{|c|c|c|c|c|}
\hline & & & Toplam & $p$ değeri \\
\hline & \multicolumn{4}{|c|}{ HIV bulaşma riskini bilme } \\
\hline & Biliyor n (\%) & Bilmiyor n (\%) & & 0,04 \\
\hline Kıdem yılı 10 yıl ve daha az & $47(\% 83,9)$ & $9(\% 16,1)$ & $56(\% 100,0)$ & \\
\hline Kıdem yılı 10 yıldan fazla & $20(\% 64,5)$ & $11(\% 35,5)$ & $31(\% 100,0)$ & \\
\hline \multirow[t]{3}{*}{ Toplam } & $67(\% 77,0)$ & $20(\% 23,0)$ & $87(\% 100,0)$ & \\
\hline & \multicolumn{4}{|c|}{ B bulaşma riskini bilme } \\
\hline & Biliyor n (\%) & Bilmiyor n (\%) & & 0,55 \\
\hline Kıdem yılı 10 yıl ve daha az & $42(\% 75,0)$ & $14(\% 25,0)$ & $56(\% 100,0)$ & \\
\hline Kıdem yılı 10 yıldan fazla & $25(\% 80,6)$ & $6(\% 19,4)$ & $31(\% 100,0)$ & \\
\hline \multirow[t]{3}{*}{ Toplam } & $67(\% 77,0)$ & $20(\% 23,0)$ & $87(\% 100,0)$ & \\
\hline & \multicolumn{4}{|c|}{ Hepatit $\mathrm{C}$ bulaşma riskini bilme } \\
\hline & Biliyor n (\%) & Bilmiyor n (\%) & & 0,64 \\
\hline Kıdem yilı 10 yıl ve daha az & $37(\% 66,1)$ & $19(\% 33,9)$ & $56(\% 100,0)$ & \\
\hline Kıdem yılı 10 yıldan fazla & $22(\% 71,0)$ & $9(\% 29,0)$ & $31(\% 100,0)$ & \\
\hline \multirow[t]{3}{*}{ Toplam } & $59(\% 67,8)$ & $28(\% 32,2)$ & $87(\% 100,0)$ & \\
\hline & \multicolumn{4}{|c|}{ Bit bulaşma riskini bilme } \\
\hline & Biliyor $n(\%)$ & Bilmiyor n (\%) & & 0,50 \\
\hline Kıdem yılı 10 yıl ve daha az & $40(\% 71,4)$ & $16(\% 28,6)$ & $56(\% 100,0)$ & \\
\hline Kıdem yılı 10 yıldan fazla & $20(\% 64,5)$ & $11(\% 35,5)$ & $31(\% 100,0)$ & \\
\hline \multirow[t]{3}{*}{ Toplam } & $60(\% 69,0)$ & $27(\% 31,0)$ & $87(\% 100,0)$ & \\
\hline & \multicolumn{4}{|c|}{ Uyuz bulaşma riskini bilme } \\
\hline & Biliyor $n(\%)$ & Bilmiyor $n(\%)$ & & 0,11 \\
\hline Kıdem yılı 10 yıl ve daha az & $37(\% 66,1)$ & $19(\% 33,9)$ & $56(\% 100,0)$ & \\
\hline Kıdem yılı 10 yıldan fazla & $15(\% 48,4)$ & $16(\% 51,6)$ & $31(\% 100,0)$ & \\
\hline Toplam & $52(\% 59,8)$ & $35(\% 40,2)$ & $87(\% 100,0)$ & \\
\hline
\end{tabular}

Hijyen konusunda hangi kaynaklardan bilgi edindikleri sorulduğunda toplam 197 cevap alındı. Cevapların \%24,4'ü (48 cevap) güncel makale, yayın ve kitaplardan, \%44,2'si (87 cevap) hijyen eğitimi şeklindeydi (Tablo:3).

Katılımcıların \%78,7'sinin (74 kişi) Hepatit B aşısı yaptırdığı ifade etti. Mezun oldukları okullara göre bakıldığında, üniversite ve daha üstündeki bir okuldan mezun olanların, lise ve daha altındaki bir okuldan mezun olanlara kıyasla yapılan ki kare testine göre anlamlı bir şekilde daha fazla Hepatit B aşısı yaptırmış olduğu bulundu $(p<0,05)$. Meslekte kıdem yılı 10 yıl ve daha az olanlar, 10 yıldan 
fazla olanlara göre istatistiksel olarak anlamlı bir şekilde daha fazla üniversite ve daha üstü bir okuldan mezun olduğu bulundu $(p<0,05)$. Çalışmaya katılan güzellik uzmanlarının Hepatit B aşısı yaptırma durumları ile meslekteki kıdem yılları arasında ve hizmet verdikleri kişi sayısı arasında yapılan ki kare testine göre anlamlı bir ilişki bulunmadı $(p>0,05)$ (Tablo:4).

\begin{tabular}{|l|l|l|}
\hline \multicolumn{3}{|l|}{ Tablo 3: Güzellik Uzmanlarının Hijyen Konusunda Bilgi Edinmek için Seçtikleri Yöntemler } \\
\hline Çalışma alanınızda hijyen konusunda bilgi edinmek & & \\
\hline için en uygun yöntem hangisidir? & Sayı(n) & Yüzde(\%)* \\
\hline Güncel makale, yayın, kitap okumak & 48 & 24,4 \\
\hline Hijyen eğitimi almak & 87 & 44,2 \\
\hline Sağlık kuruluşlarından bilgi almak & 32 & 16,2 \\
\hline İnternetten araştırma yapmak & 28 & 14,2 \\
\hline İş sağlığı ve güvenliği hizmetlerinden bilgi almak & 2 & 1,0 \\
\hline Toplam cevap sayısı & 197 & 100,0 \\
\hline *:Yüzdeler toplam cevap sayısı üzerinden hesaplanmıştı. & \\
\hline
\end{tabular}

Tablo 4: Güzellik uzmanlarının Hepatit B aşısı yaptırma durumları ve meslekteki kıdem yılları, mezun oldukları okullar ve hizmet verdikleri kişi sayısı arasındaki ilişki

\begin{tabular}{|c|c|c|c|c|c|}
\hline & & $\begin{array}{c}\text { Hepatit B aşısı } \\
\text { var }\end{array}$ & $\begin{array}{l}\text { Hepatit B aşısı } \\
\text { yok }\end{array}$ & Toplam & P değeri \\
\hline \multirow[t]{4}{*}{$\begin{array}{l}\text { Meslekteki kıdem yılları } \\
\text { n (\%) }\end{array}$} & & & & & 0,79 \\
\hline & 10 yıl ve daha az & $43(\% 78,2)$ & $12(\% 21,8)$ & 55 & \\
\hline & 10 yıldan fazla & $25(\% 80,6)$ & $6(\% 19,4)$ & 31 & \\
\hline & Toplam & 68 & 18 & 86 & \\
\hline \multirow[t]{4}{*}{ Mezun olunan okul n (\%) } & & & & & $0,00^{*}$ \\
\hline & Lise ve daha az & $44(\% 69,8)$ & $19(\% 30,2)$ & 63 & \\
\hline & $\begin{array}{l}\text { Üniversite ve daha } \\
\text { fazla }\end{array}$ & $30(\% 96,8)$ & $1(\% 3,2)$ & 31 & \\
\hline & Toplam & 74 & 20 & 94 & \\
\hline \multirow[t]{4}{*}{$\begin{array}{l}\text { Hizmet verilen kişi sayısı } \\
\mathrm{n}(\%)\end{array}$} & & & & & 0,11 \\
\hline & 10 ve daha az & $33(\% 71,7)$ & $13(\% 28,3)$ & 46 & \\
\hline & 10 dan fazla & $41(\% 85,4)$ & $7(\% 4,6)$ & 48 & \\
\hline & Toplam & 74 & 20 & 94 & \\
\hline
\end{tabular}

Birden fazla seçenek işaretleyebilecekleri belirtilerek sorulan kullandıkları araç gereçlerin dezenfeksiyonunu sağlama yöntemleri sorusuna, 98 katılımcıdan toplam 162 yanıt alındı. Bu cevapların \%7,4'ünü (12 cevap) '20 dakika kaynatarak', \%8,6'sı (14 cevap) 'çamaşır suyunda bekleterek', \%37,0'וn (60 cevap) 'ultraviyole sterilizatör kullanarak', \%18,5'ini (30 cevap) 'otoklav kullanarak', \%25,9’unu (42 cevap) 'dezenfektan solüsyonlar ile’ yanıtı oluşturdu.

86 katılımcının cevap verdiği kalıcı makyaj iğnelerini nasıl dezenfekte ettikleri sorusuna \%91,9'u (79 kişi) tek kullanımlık iğne kullandığını belirtti (Tablo:5).

Katılımcılara sorulan el hijyenini nasıl sağladıkları sorusuna verilen 198 cevaptan \%16,1'ini (32 cevap) 'ellerimi sabunla yıkayıp sonra eldiven takıyorum' \%45,9'unu (91 cevap) 'sadece eldiven takıyorum', \%34,8'ini (69 cevap) 'ellerimi sabunla yıkadıktan sonra dezenfektanla temizleyip eldi-
Sakarya Tip Dergisi

2018;8(1):70-79

SÖZEN ve Ark.

Güzellik Uzmanlarinda Bulaşıcı Hastalık

ve Hijyen Bilgi Tutum 
Sakarya Tıp Dergisi

2018;8(1):70-79

SÖZEN ve Ark. Gïzellik Uzmanlarında Bulașc Hastalk ve Hijyen Bilgi Tutum ven takıyorum' cevapları oluşturdu (Tablo:5).

Katılımcılar işlem öncesi cilt temizliği için \%40,3 (56 cevap) firmaların önerdiği hazır antiseptik solüsyonları, \%5,8 (8 cevap) kolonya, \%26,7 (37 cevap) alkol, \%23,7 (33 cevap) biokadin kullandığını belirtti (Tablo:5).

Katılımcılar sir ağda yaparken hijyenin nasıl sağlandığı konusunda \%72,4’ü (63 cevap) kişiye özel kartuş açtığını, \%10,4’ü (9 cevap) kartuşun başlığı değiştirdiğini, \%12,6’sı (11 cevap) kavanoz ağda kullanıp her batırışta farklı spatula kullandığını, \%4,6'sı (4 cevap) kavanoz ağda kullanıp her müşteride aynı spatulayı kullandığını bildirdi (Tablo:5)

Tablo 5: Gïzellik uzmanlarının bazı kişisel hijyen ve dezenfeksiyon uygulamalarıyla ilgili tercihleri

\begin{tabular}{|c|c|c|}
\hline & Sayı (n) & $\begin{array}{l}\text { Yüzde } \\
(\%)\end{array}$ \\
\hline \multicolumn{3}{|l|}{ *işlem öncesi cilt temizliği için hangi ürünleri tercih ediyorsunuz? ( $\mathbf{n = 9 2 )}$} \\
\hline Firmaların önerdiği hazır antiseptik solüsyonlar & 56 & 40,3 \\
\hline Kolonya & 8 & 5,8 \\
\hline Alkol & 37 & 26,7 \\
\hline Biokadin(tentürdiyot) & 33 & 23,7 \\
\hline Islak mendil & 1 & 0,7 \\
\hline Diğer & 4 & 2,9 \\
\hline Toplam cevap sayısı & 139 & 100,0 \\
\hline \multicolumn{3}{|l|}{ *El hijyenini nasıl sağlıyorsunuz? (n=95) } \\
\hline Ellerimi sabunla yıkayıp sonra eldiven takıyorum & 32 & 16,1 \\
\hline Sadece eldiven takıyorum & 91 & 45,9 \\
\hline Ellerimi sabunla yıkadıktan sonra dezenfektanla temizleyip eldiven takıyorum & 69 & 34,8 \\
\hline Kolonya ile & 3 & 1,5 \\
\hline Islak mendil ile & 2 & 1,0 \\
\hline Çift eldiven kullanıyorum & 1 & 0,5 \\
\hline Toplam cevap sayısı & 112 & 100,0 \\
\hline \multicolumn{3}{|c|}{$\begin{array}{l}\text { *Kullandığınız araç gereçlerin dezenfeksiyonunu hangi yöntemlerle yapıyorsunuz? } \\
\text { (n=98) }\end{array}$} \\
\hline $20 \mathrm{dk}$ kaynatarak & 12 & 7,4 \\
\hline Çamaşır suyunda bekleterek & 14 & 8,6 \\
\hline Ultraviyole sterilizatör kullanarak & 60 & 37,0 \\
\hline Otoklav kullanarak & 30 & 18,5 \\
\hline Dezenfektan solüsyonlar ile & 42 & 25,9 \\
\hline Tek kullanımlık ürün kullanıyorum & 3 & 1,8 \\
\hline Yüksek ısı kullanarak & 1 & 0,6 \\
\hline Toplam cevap sayısı & 162 & 100,0 \\
\hline \multicolumn{3}{|l|}{ Güzellik Uzmanlarının Sir Ağda Uygulamasında Kullandığı Hijyenik Yöntemler } \\
\hline Kişiye özel kartuş açıyorum & 63 & 72,4 \\
\hline Aynı kartuşu kullanıyorum, başlığı değiştiriyorum & 9 & 10,4 \\
\hline Kavanoz ağda kullanıp her batııışta farkıı spatula kullanıyorum & 11 & 12,6 \\
\hline Kavanoz ağda kullanıp her müşteride aynı spatulayı kullanıyorum & 4 & 4,6 \\
\hline Toplam & 87 & 100,0 \\
\hline
\end{tabular}


Sağlık kontrollerini, katılımcıların \%17,5'i (14 kişi) ayda bir, \%12,5'i (10 kişi) üç ayda bir, \%38,8'i (31 kişi) altı ayda bir, \%21,3’ü (17 kişi) yılda bir yaptırmaktadır. \%7,5’i (6 kişi) sağık kontrollerini yaptırmadığını belirtti.

\section{Tartışma}

22.10.2017 tarihinde Antalya'da bir kongreye tüm Türkiye'den katılan güzellik uzmanları üzerinde yapılan araştırmaya 98 güzellik uzmanı katıldı. Katılımcıların \%91,7'si (88 kişi) kadın, yaşlarının ortalaması $36,21 \pm 8,93$ yıl, çalışma yıllarının ortalaması 9,8 $\pm 7,57$ yıldı.

Ankara'da kuaför ve güzellik salonlarında çalışan kişilerde yapılan bir çalışmada meslekte ortalama çalışma süresi $5.56 \pm 5.735$ olarak bulunmuştur.4 Bizim çalışmamızda çalışma yıllarının daha yüksek olmasının nedeni, çalışmaya katılanların hepsinin güzellik uzmanı olup, kuaförlerde çalışan diğer kişilere anket yapılmamış olması olabilir.

Çalışmamızda katılımcıların çoğunu \%59,2 (58 kişi) ile lise mezunları oluşturdu. Manisa'da berber, kuaför ve güzellik salonlarında çalışan kişilerde yapılan bir çalışmada çalışmaya katılanların büyük çoğunluğunu ilkokul mezunları oluşturmuştur.5 Katılımcıların çoğunun lise mezunu olmasının nedeninin, çalışmaya sadece güzellik uzmanlarının katılmasından dolayı olabileceği düşünüldü.

Güzellik salonlarıyla ilişkili bulaş riski olan hastalıkları araştıran sorumuza 95 katılımcı cevap verdi. \%75,8'i (72 kişi) HIV (AIDS) bulaşabileceğini, \%74,7’ü (71 kişi) Hepatit B bulaşabileceğini ifade etti. i̇stanbul'da bayan kuaförlerde yapılan bir çalışmada araştırmaya katılanların sadece yarısı Hepatit B, HIV gibi mesleki uygulamalarla bulaşabilecek hastalıkları bilmektedir.6 Aksaray il merkezinde kuaför çalışanlarında yapılan bir çalışmada katılımcların \%64,4'ü dikkat edilmediği takdirde müşterisinden kendisine hepatit B bulaşabileceğini düşünmektedir.9 Ankara'da çalışmaya katılan kuaför, berber ve güzellik salonunda çalışanların işyerlerinden bulaşabilecek hastalıklarla ilgili görüşlerinin sorulduğu bir araştırmada, katılımcıların \%61,9'u hepatit B bulaşma riskini, \%57,1'i HIV bulaşma riskini doğru tahmin etmiştir.7 Literatürdeki diğer çalışmalara göre bizim çalışmamızda daha fazla kişi bu hastalıkları bilmekteydi. Bu durumun güzellik uzmanlığı eğitiminde bu hastalıklarla ilgili eğitim almış olmaları nedeniyle olabileceği düşünüldü.

Araştırmamıza katılan kişiler arasında kıdem yılı 10 yıl ve daha az olanlar, 10 yıldan daha fazla meslekte kıdemli olanlara göre HIV enfeksiyonun güzellik salonlarından bulaşabileceğini anlamlı olarak daha doğru tahmin etti $(p<0,05)$. Ankara'da yapılan bir çalışmada meslekte çalışma süresi ile kan yoluyla bulaşan hastalıkları bilme arasında istatistiksel olarak anlamlı bir ilişki bulunmamıştır ( $p=0.54) .4$ Bizim çalışmamızda meslekte kıdem yılı 10 yıl ve daha az olanların HIV enfeksiyonu konusundaki doğru tahminleri daha fazladır. Bunun nedeni 10 yıldan az kıdemli grupta üniversite mezunu olanların daha yüksek olması olabilir.

Araştırmaya katılanların \%65,3'ü yer ve yüzey temizliğini çamaşır suyu katılmıs su ile yaptığını bildirdi. Bununla birlikte katılımcıların \%42,1'i yer ve yüzey temizliği için deterjan kullandığını ifade etti. Bornova'da manikür ve pedikür yapan çalışanlarda yapılan bir araştırmada, katılımcıların tezgah, ayna, zemin ve oturma gruplarının temizliğinde çamaşır suyu kullanımı \%71,5 olarak bulunmuştur.8 Bizim çalışmamıza yakın oranlar görüldü.
Sakarya Tıp Dergisi 2018;8(1):70-79

SÖZEN ve Ark. Güzellik Uzmanlarinda Bulașıı Hastalk ve Hijyen Bilgi Tutum 
için gereklidir.

Kuaför, güzellik salonu vb yerlerde çalışanlar, bu yerlerden hizmet alanlar ve dolayısılya toplum sağı̆ğı açısından, bu yerlerin çok sıkı denetlenmesi ve çalışanların aşı ve sağlık kontrollerinin yaptırılmasının sağlanması çok önemlidir. Meslek odası ve diğer sorumlu kuruluşların, hizmet içi eğitim çalışmalarını artırmaları gerekmektedir.
Sakarya Tip Dergisi

2018;8(1):70-79

SÖZEN ve Ark.

Güzellik Uzmanlarnnda Bulașıcı Hastalik

ve Hijyen Bilgi Tutum 
1. Canyılmaz D, Berber ve kuaför hizmetlerinde DAS uygulamaları, Ulusal Sterilizasyon Dezenfeksiyon Kongre Kitabı; İzmir, 2009; 407-16.

2. Türkiye'de bildirilen HIV/AIDS vakalarının yıllara göre dağılımı. Available at: http://www.hatam.hacettepe.edu.tr/ verilerHaziran2016web.pdf Published June 2016. Accessed January 30, 2017.

3. Toy M, Önder FO, Wörmann T, et al. Age- and region- specific hepatitis $B$ prevalence in Turkey estimated using generalized linear mixed models: a systematic review. BMC Infect Dis 2011;12:337- 49.

4. Boztaș G, Çilingiroğlu N, Özvarıs S, Karaöz A, Karataș F, Kara G, et al. Ankara İlinin Bir Semtinde Bulunan Kuaför ve Güzellik Salonlarında Çalısan Kişilerin Kan Yoluyla Bulaşan Hastalıklar Konusunda Bazı Görüş ve Uygulamaları, Hemşirelik Yüksekokulu Dergisi, 2006; 60-68.

5. Togan T, Turan H, Tosun S, Arslan H. Manisa II Merkezinde Berber, Kuaför Ve Güzellik Salonu Çalışanlarının Hepatit Konusundaki Bilgi Düzeyi, Tutum ve Davranışları. ANKEM Dergisi, 2014; 28(2):50-57.

6. Şahin NH, Bilgiç D, Esen Ü, Çetinkaya R, Tozoğlu Z. Bayan Kuaförü Çalışanlarının Hepatit B'ye Ilişkin Bilgi ve Uygulamalarının Belirlenmesi, TAF Preventive Medicine Bulletin, 2009; 8(2), 147-154.

7. Üner S, Özvarış ŞB. Kan Yoluyla Bulaşan Hastalıklardan Korunmada Farklı Bir Hedef Grup İçin Eğitim Programı. Toplum Hekimliği Bülteni, 2001; Sayı 2, S. 1-4.

8. Durusoy R, Mermer G, Türk Soyer M. Bornova'da meslek odasına kayıtlı işyerlerinde manikür-pedikür çalışanlarının enfeksiyonu önleme konusunda bilgi ve davranışları. Ege Tıp Dergisi, 2012; 51(2):83-91.

9. Togan T, Tosun S, Turan H, Arslan H. Aksaray il merkezinde kuaför çalışanlarının hepatit konusundaki bilgi düzeyi ve davranışları, Ege Tıp Dergisi, 2014; 53(4), 189-194. 